\title{
Correlation of patient-reported numbness around surgical scars with patient-reported outcome measures and joint awareness after knee replacement: a cohort study
}

Masafumi Itoh, Junya Itou, Umito Kuwashima and Ken Okazaki

\begin{abstract}
Background: Knee replacement is a very effective and indispensable treatment option for end-stage knee arthritis, and the number of cases has been increasing worldwide. A replaced knee joint without patient joint awareness is thought to be the ultimate goal of artificial knees. Joint awareness reportedly correlates with patient satisfaction. Although numbness around a replaced knee is a minor but common problem, its effect on postoperative outcome is controversial. Joint awareness also is sensitive to subtle abnormalities of the joint, so it must be negatively affected by numbness. Although numbness is minor, it cannot be ignored to further improve knee replacement outcomes. This study investigated the relationship between patient-reported numbness and other patient-reported outcome measures (PROMs), including joint awareness, and kneeling. We developed a numbness score based on a 5-point Likert scale on frequency of numbness, with an intraclass correlation coefficient of 0.76 and higher scores indicating less numbness.
\end{abstract}

Methods: The numbness score, New Knee Society Score (KSS), Knee Injury and Osteoarthritis Outcome Score (KOOS), Forgotten Joint Score-12 (FJS-12), and other clinical and radiological data from 311 patients (394 primary knee replacements) were analyzed. Kneeling ability was evaluated by using kneeling-specific items in the KSS (KSS-Kneeling).

Results: No numbness was found in 170 knees (43.1\%), and some degree of numbness was found in the remaining 224 knees (56.9\%). The numbness score showed weak-to-moderate correlations with KSS-Symptoms $(r=0.44)$, KSS-Satisfaction $(r=0.41)$, KSS-Activities $(r=0.29)$, and all KOOS subscales $(r=0.23-0.44)$, and FJS-12 $(r=0.42)$. Multiple regression analyses suggested that midline incision positively affected the numbness score over the anteromedial incision ( $p=0.04)$ and that a better numbness score $(p=0.001)$, male sex $(p<0.0001)$, and better postoperative knee flexion angle (0.04) positively affected kneeling.

Conclusions: The numbness score positively correlated with PROMs and positively affected kneeling. Knee replacements performed via an anteromedial incision may be at higher risk for numbness.

Keywords: Knee replacement, Numbness, Joint awareness, Forgotten joint Score-12, Kneeling

*Correspondence: okazaken@gmail.com

Department of Orthopaedic surgery, Tokyo Women's Medical University,

8-1, Kawada-Cho, Shinjuku-ku, Tokyo 162-8666, Japan

\section{Background}

Knee arthroplasty is an effective treatment option for osteoarthritis (OA), osteonecrosis $(\mathrm{ON})$, and rheumatoid arthritis (RA) of the knee [1-6]. Especially in the original author(s) and the source, provide a link to the Creative Commons licence, and indicate if changes were made. The images or other third party material in this article are included in the article's Creative Commons licence, unless indicated otherwise in a credit line to the material. If material is not included in the article's Creative Commons licence and your intended use is not permitted by statutory regulation or exceeds the permitted use, you will need to obtain permission directly from the copyright holder. To view a copy of this licence, visit http://creativecommons.org/licenses/by/4.0/. The Creative Commons Public Domain Dedication waiver (http://creativeco mmons.org/publicdomain/zero/1.0/) applies to the data made available in this article, unless otherwise stated in a credit line to the data. 
end-stages of these conditions when there is no alternative treatment available, knee arthroplasty is a very effective and indispensable technique [6]. In 2010, knee replacement in the United States was performed in $1.5 \%$ of the general population and $10.4 \%$ of the population $>80$ years old [7], and the number of cases is expected to increase worldwide $[8,9]$. Major complications, such as deep infection, loosening, and instability, often require revision surgery, whereas minor complications, such as discomfort around the scar [10] and noise from the knee [11], seldom require revision. In addition, minor complications related to wounds are relatively common [12], and wound-related complications have potential risks of developing into major complications that require further surgery. Other researchers have reported that $46-98 \%$ of patients who underwent knee replacement complained of numbness around the knee postoperatively [10, 13, 14]. Jariwala et al. [13] reported that 53\% of 258 total knee arthroplasties (TKAs) resulted in complaints of numbness around the operated knee, but the numbness did not correlate with patient-reported outcome measures (PROMs), such as the New Knee Society Score (KSS) [15] at 1 year after the surgery. Blackburn et al. [14] reported that $68 \%$ of 56 TKAs resulted in complaints of numbness but the numbness did not correlate with the Western Ontario and McMaster Universities Osteoarthritis Index (WOMAC) score [16] or the Knee Injury and Osteoarthritis Outcome Score (KOOS) [17]. However, Blackburn et al. also found that numbness around the operated knee correlated with kneeling difficulty and that kneeling difficulty correlated with poor results of WOMAC and KOOS. In fact, it was reported that $56-82 \%$ of patients who underwent knee arthroplasty complained of kneeling difficulty $[11,18,19]$. Therefore, although numbness around the replaced knee is a relatively common minor complication, how it may be associated with clinical outcomes remains controversial.

It is assumed that numbness is related to discomfort rather than pain that most conventional PROMs aim to assess. In 2012, Behrend et al. developed the Forgotten Joint Score-12 (FJS-12) [20] as a PROM that evaluates joint awareness, detects subtle discomfort, has a low ceiling effect, and was found to be useful in evaluating joint replacements. Subsequently, many authors have used the FJS-12 to report the outcomes of knee replacement [21-25]. Although some authors found that numbness after knee replacement did not correlate with conventional PROMs [11, 13, 14], the FJS-12, which assesses joint awareness, may be able to detect the effect of numbness. To further improve knee replacement outcomes, although numbness is minor, it cannot be ignored.

This study aimed to investigate the correlation between numbness around the surgical scar after knee replacement and PROMs, including the FJS-12, and to assess the influence of this numbness on kneeling in a larger cohort than in previous studies $[10,11,13,14$, 26]. We hypothesized that worse numbness would be correlated with poorer postoperative PROMs and would adversely affect kneeling.

\section{Methods}

\section{Patients and data collection}

This retrospective cohort study was approved by the institutional ethics committee of Tokyo Women's Medical University, Tokyo, Japan (approval number 4578) and performed in accordance with the ethical standards of the Declaration of Helsinki. We retrospectively investigated 514 knee replacements in 404 patients performed at our institution between May 2007 and January 2019. All procedures were performed by any of five specialist knee surgeons who were trained in both knee replacement and sports medicine.

Unicondylar knee arthroplasty (UKA) was indicated for patients diagnosed with medial OA or medial ON of the knee with varus malalignment of $<20^{\circ}$ and flexion contracture of $<20^{\circ}$ in which the anterior and posterior cruciate ligaments were functional, and the lateral and patellofemoral compartments were healthy or asymptomatic with very mild changes. TKA was indicated for patients diagnosed with other than knee infection without limitation of the malalignment degree, movement restriction range, impaired compartments number, and cruciate ligament residual function. The postoperative alignment of TKA was aimed for mechanical alignment, where the hip, knee, and ankle centers were aligned in a straight line in the coronal plane [27] using conventional instruments without computer navigation or robotic assisted surgery. The inclusion criteria were patients who underwent primary UKA or TKA without restrictions on body mass index (BMI), age, worker compensation status, or psychiatric disorders such as anxiety and depression. The exclusion criteria were revision knee arthroplasty, past major knee surgery (such as ligament reconstruction or knee osteotomy on the same knee), any additional surgery on the same knee, and incomplete records. Five knees had undergone additional surgery before the survey: three patients with three TKAs underwent irrigation and insert exchange due to infection, one patient following a UKA underwent open reduction of a dislocated mobile bearing insert, and one patient following a UKA underwent an arthroscopically assisted hemostatic procedure for hemarthrosis. Consequently, 439 knees in 345 patients met the eligibility criteria. After exclusion of fatal cases and patients who were lost to follow-up, 394 knees in 311 patients were enrolled in the study (followup rate, 89.7\%; Fig. 1). 


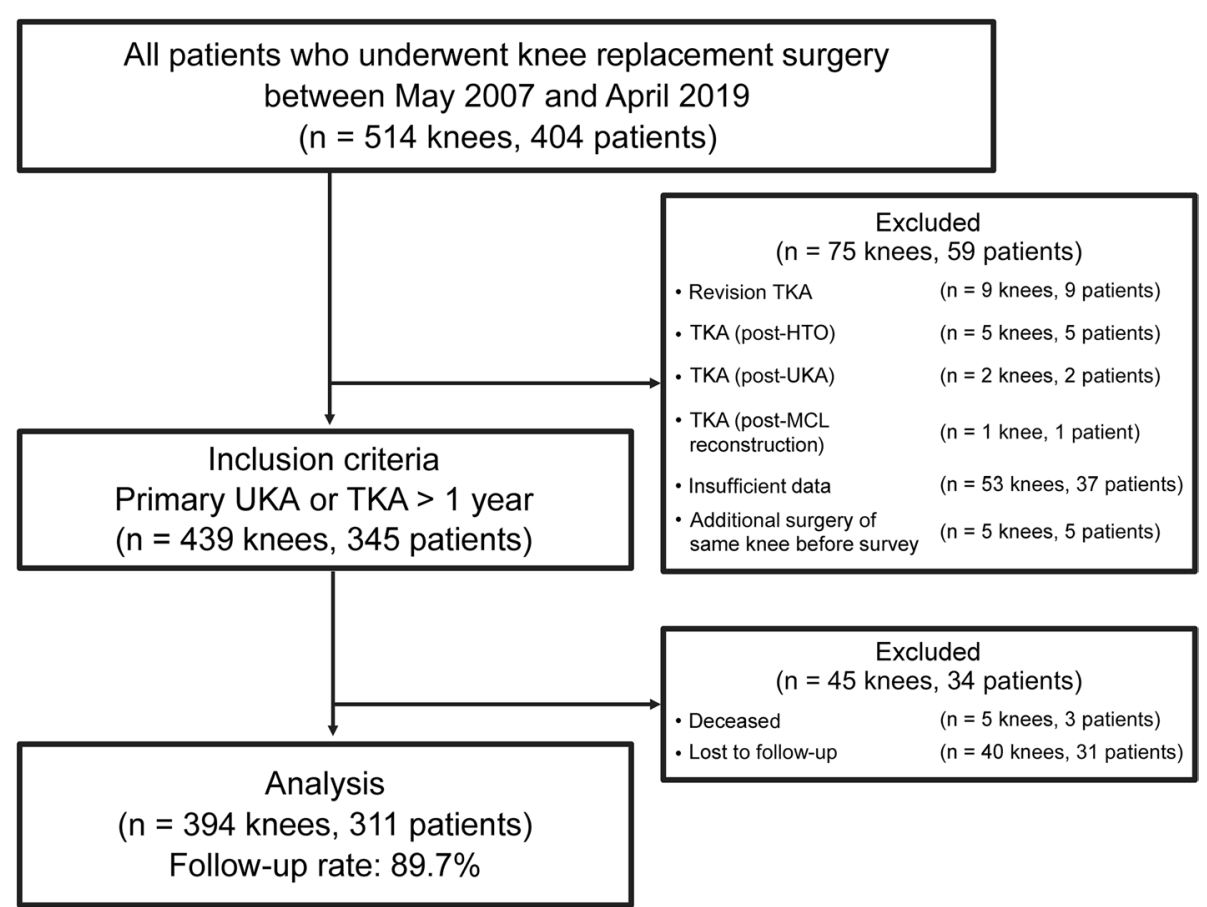

Fig. 1 Flowchart for this retrospective study. The flowchart shows the cohort of patients who underwent knee replacement surgery at our institution, surgical details, mortality, and loss to follow-up. HTO, high tibial osteotomy; MCL, medial collateral ligament; TKA, total knee arthroplasty; UKA, unicondylar knee arthroplasty

A post-hoc power analysis was calculated by using G*power (version 3.1.9.3, Institut für Experimentelle Psychologie, Heinrich Heine Universität, Dusseldorf, Germany). An effect size of 0.42 (see the result section) was calculated on the basis of Spearman's correlation coefficients between the FJS-12 and numbness score. A power greater than 0.99 was calculated by using the effect size, sample size of 394 knees, and alpha level of 0.01 .

Demographic and clinical data, including sex, age at surgery, age at survey completion, follow-up (months), BMI, diagnosis, preoperative Kellgren-Lawrence (K-L) [28] grading, surgical method used (UKA or TKA), type of skin incision (midline or anteromedial), type of arthrotomy (medial parapatellar, midvastus, trivector, or subvastus), and preoperative and postoperative extension and flexion angles of the knee were collected from the medical records and radiographs. Postoperatively, written informed consent and the KSS, KOOS, FJS-12, and numbness score (as described below) were obtained for each patient. The questionnaire item on kneeling in the KSS was defined as "KSS-Kneeling" and was used to assess kneeling ability. If a patient had undergone bilateral knee arthroplasty, the data for each knee were collected separately. Postoperative data, including PROMs, were collected at a minimum of 1 year postoperatively.
Table 1 shows the clinical and demographic data of the 394 knees in 311 patients. In total, 339 knees were diagnosed as OA and graded by using the K-L grading system. All UKAs were mobile bearing UKA (Oxford unicompartmental knee prosthesis. Zimmer Biomet Ltd., Bridgend, UK) via an anteromedial incision and midvastus approach. A midline or anteromedial incision and one of the arthrotomy approaches (medial parapatellar, trivector, midvastus, or subvastus) were selected for the TKA at the discretion of the surgeon.

\section{Numbness score}

Given the subjective nature of numbness, the numbness score for this study was devised using a Likert scale-type questionnaire that had the same question format as that of the FJS-12 questionnaire. Patients were asked "Are you aware of numbness that bothers you around the surgical scar of your operated knee?" and were then asked to choose a reply from one of the following: "never," "almost never," "seldom," "sometimes," or "mostly," which were assigned 4, 3, 2, 1, and 0 points, respectively. This meant that higher is the numbness score, less is the numbness. To calculate intraclass correlation (ICC) as a measure of numbness score reliability, the numbness scores were 
Table 1 Demographics of 394 knees (311 patients)

\begin{tabular}{ll}
\hline Men: \% (number of knees) & $20.0 \%$ (79 knees) \\
Age at surgery (years) & $72.9 \pm 8.2$ \\
Age at survey completion (years) & $75.2 \pm 8.2$ \\
Follow-up (months) & $28.0 \pm 25.2$ \\
BMl at survey completion (kg/m²) & $25.5 \pm 4.3$ \\
Diagnosis: \% (number of knees) & OA: $86.0 \%(339)$ \\
& ON: $7.4 \%(29)$ \\
& RA: $6.6 \%(26)$ \\
Preoperative K-L grade of 339 knees & Grade 1: 0.3\% (1) \\
diagnosed OA: & Grade 2: 5.6\% (19) \\
\% (number of knees) & Grade 3: $18.9 \%(64)$ \\
& Grade 4: $75.2 \%(255)$ \\
Surgical method: \% (number of knees) & TKA: $81.2 \%(320)$ \\
& UKA: $18.8 \%(74)$ \\
Skin incision: \% (number of knees) & Midline: $51.5 \%(203)$ \\
& Anteromedial: 48.5\% (191) \\
Arthrotomy: \% (number of knees) & Medial parapatellar: 25.4\% (100) \\
& Trivector: $3.5 \%(14)$ \\
& Midvastus: $22.6 \%(89)$ \\
& Subvastus: $48.5 \%(191)$
\end{tabular}

$B M I$ Body mass index, $K-L$ Kellgren-Lawrence, OA Osteoarthritis, ON Osteonecrosis, RA Rheumatoid arthritis, TKA Total knee arthroplasty, UKA Unicondylar knee arthroplasty

collected twice at intervals of $\leq 1$ month from 40 randomly selected individuals included in the analysis.

\section{Statistical analysis}

JMP Pro version 13.2.1 (SAS Institute Inc., Cary, NC, USA) was used. A $p$-value of $<0.05$ was considered to be indicative of statistical significance. The Wilcoxon signedrank test was used to evaluate differences between the pre- and postoperative numerical data. The differences in means between two groups were evaluated by performing the Mann-Whitney $U$-test. Spearman's correlation coefficient was used to analyze correlations between the numbness score and each PROM. Table 2 shows the strength of the correlation coefficient $(r)$ [29]. In addition, univariable and multivariable regression analyses with the numbness score and KSS-Kneeling as the response variables were performed to correct the confounding bias. The ICC $(2,1)$ of the numbness score was calculated

Table 2 Definition of the strength of the correlation coefficients

\begin{tabular}{ll}
\hline Range of correlation coefficients $(\boldsymbol{r})$ & $\begin{array}{l}\text { Strength } \\
\text { of the } \\
\text { correlation }\end{array}$ \\
\hline $0 \leq r<0.1$ & Negligible \\
$0.1 \leq r<0.4$ & Weak \\
$0.4 \leq r<0.7$ & Moderate \\
$0.7 \leq r<0.9$ & Strong \\
$0.7 \leq r<1.0$ & Very strong \\
\hline
\end{tabular}

[30]. The test-retest reliability of the numbness score was confirmed, with an $\operatorname{ICC}(2,1)$ of 0.76 .

\section{Results}

Preoperative flexion contracture was significantly greater in knees scheduled for TKA than for UKA $(p<0.0001)$. Postoperative flexion contracture was comparable between both groups $(p=0.32)$. Preoperative flexion was significantly less in knees scheduled for TKA than UKA $(p<0.0001)$. Postoperative flexion was significantly less in TKAs than UKAs $(p<0.0001)$. Postoperatively, both groups significantly improved in both extension and flexion $(p<0.0001)$ (Table 3$)$.

A histogram of the numbness scores for the 394 knees showed that no numbness (numbness score $=4$ points) was found in $170(43.1 \%)$ knees and that some degree of numbness (numbness score $\leq 3$ points) was found in the remaining 224 (56.9\%) knees (Fig. 2). Since the distribution of numbness scores was quite skewed, with $43.1 \%$ having a numbness score of 4 , the ICC $(2,1)$ for the subset of patients who reported at least some numbness (score 0-3) was calculated and was found to be 0.68 .

The results for each PROM were obtained from the last follow-up. The median numbness score in this cohort was 3 points (almost never aware of numbness around the surgical scar of the operated knee). For KSS-Kneeling, 0 points is the lowest score (cannot kneel) and 5 points is the highest score (can kneel without aggravation or numbness bother). The median score on the KSSKneeling was 2 points (kneel with severe discomfort). Therefore, kneeling after knee replacement in the entire cohort showed a high degree of discomfort (Table 4).

The numbness score showed weak to (0.19-0.39) moderate (0.41-0.44) correlations with each PROM and its subscales (Table 5 ).

Table 3 Comparison of preoperative and postoperative knee extension and flexion angle by surgical method

\begin{tabular}{|c|c|c|c|}
\hline Type of surgery & TKA: 320 knees & UKA: 74 knees & $p$-value \\
\hline \multicolumn{4}{|c|}{ Knee extension angle $\left(^{\circ}\right)$} \\
\hline Preoperative & $8.7 \pm 8.3$ & $3.6 \pm 4.6$ & $<0.0001$ \\
\hline Postoperative & $0.7 \pm 2.3$ & $0.3 \pm 1.5$ & 0.32 \\
\hline$p$-value & $<0.0001$ & $<0.0001$ & \\
\hline \multicolumn{4}{|c|}{ Knee flexion angle $\left(^{\circ}\right)$} \\
\hline Preoperative & $123.5 \pm 15.7$ & $132.8 \pm 11.0$ & $<0.0001$ \\
\hline Postoperative & $132.8 \pm 1.0$ & $137.0 \pm 8.0$ & $<0.0001$ \\
\hline$p$-value & $<0.0001$ & $<0.0001$ & \\
\hline \multicolumn{4}{|c|}{$\begin{array}{l}\text { The knee extension angle is expressed as a negative value for hyperextension } \\
\text { and a positive value for limitation of extension. }\end{array}$} \\
\hline \multicolumn{4}{|c|}{ Boldface means statistically significant. } \\
\hline \multicolumn{4}{|c|}{ TKA Total knee arthroplasty, UKA Unicondylar knee arthroplasty } \\
\hline
\end{tabular}




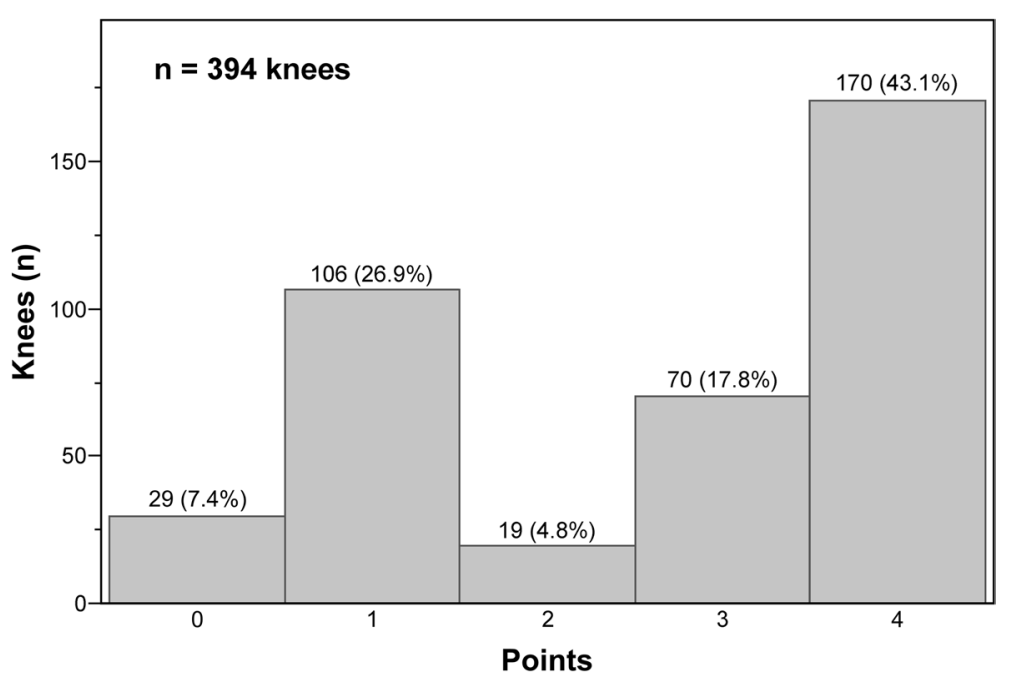

Fig. 2 Histogram showing the numbness scores for 394 knees. A score of 4 points indicates no numbness

The univariable and multivariable regression analyses with the numbness score as the response variable suggested that the numbness score was better after midline incision than after anteromedial incision (Table 6).

The univariable and multivariable regression analyses with KSS-Kneeling as the response variable suggested that male sex, better postoperative knee flexion, and better numbness score were factors associated with better kneeling ability (Table 7).

Table 4 Numerical data for each PROM, including numbness score and KSS-Kneeling

\begin{tabular}{lllll}
\hline Scales of PROMs & Mean & Median & SD & Range \\
\hline Numbness score: (0-4 points) & 2.6 & 3 & 1.5 & $0-4$ \\
KSS & & & & \\
$\quad$ Symptoms: (0-25 points) & 19.7 & 21 & 5.8 & $0-25$ \\
Satisfaction: (0-40 points) & 27.6 & 28 & 8.5 & $0-40$ \\
Expectation: (0-15 points) & 9.9 & 9 & 2.8 & $0-15$ \\
Activities: (0-100 points) & 66.3 & 69 & 20.1 & $0-100$ \\
Total: (0-180 points) & 123.5 & 126 & 30.8 & $6-178$ \\
Kneeling: (0-5 points) & 1.8 & 2 & 1.7 & $0-5$ \\
KOOS & & & & \\
Symptom: (0-100 points) & 82.4 & 85.7 & 14.3 & $21.4-100$ \\
Pain: (0-100 points) & 82.5 & 86.1 & 16.7 & $16.7-100$ \\
ADL: (0-100 points) & 79.6 & 83.8 & 16.5 & $21.6-100$ \\
Sports: (0-100 points) & 43.4 & 45 & 28.9 & $0-100$ \\
QOL: (0-100 points) & 60.7 & 62.5 & 24.6 & $0-100$ \\
FJS-12: (0-100 points) & 45.3 & 42.7 & 26.0 & $0-100$ \\
\hline
\end{tabular}

ADL Activities of daily living, FJS-12 Forgotten Joint Score-12, KOOS Knee Injury and Osteoarthritis Outcome Score, KSS New Knee Society Score, PROM Patientreported outcome measure, QOL Quality of life, SD Standard deviation

\section{Discussion}

The most important findings of this study were that greater numbness (lower numbness score) correlated with poor postoperative PROMs and greater numbness adversely affected kneeling. Therefore, our hypothesis was verified. The numbness score had moderate correlations with PROMs related to symptoms, joint awareness, and satisfaction. Multivariate regression analysis revealed that compared with midline incision, anteromedial incision was a risk factor for a worse (lower) numbness score.

Table 5 Correlations between the numbness score and each PROM

\begin{tabular}{llll}
\hline PROMs & Correlation & $\mathbf{9 5 \% ~ C l}$ & $\boldsymbol{p}$-value \\
\hline KSS & & & \\
Symptoms & $0.44^{\mathrm{b}}$ & $0.35-0.51$ & $<\mathbf{0 . 0 0 0 1}$ \\
Satisfaction & $0.41^{\mathrm{b}}$ & $0.32-0.49$ & $<\mathbf{0 . 0 0 0 1}$ \\
Expectation & $0.19^{\mathrm{a}}$ & $0.09-0.28$ & $<\mathbf{0 . 0 0 0 1}$ \\
Activities & $0.29^{\mathrm{a}}$ & $0.21-0.39$ & $<\mathbf{0 . 0 0 0 1}$ \\
Total & $0.39^{\mathrm{a}}$ & $0.30-0.47$ & $<\mathbf{0 . 0 0 0 1}$ \\
KOOS & & & \\
Symptom & $0.42^{\mathrm{b}}$ & $0.34-0.50$ & $<\mathbf{0 . 0 0 0 1}$ \\
Pain & $0.44^{\mathrm{b}}$ & $0.36-0.52$ & $<\mathbf{0 . 0 0 0 1}$ \\
ADL & $0.36^{\mathrm{a}}$ & $0.27-0.44$ & $<\mathbf{0 . 0 0 0 1}$ \\
Sports & $0.23^{\mathrm{a}}$ & $0.13-0.32$ & $<\mathbf{0 . 0 0 0 1}$ \\
QOL & $0.38^{\mathrm{a}}$ & $0.29-0.46$ & $<\mathbf{0 . 0 0 0 1}$ \\
FJS-12 & $0.42^{\mathrm{b}}$ & $0.33-0.49$ & $<\mathbf{0 . 0 0 0 1}$ \\
\hline
\end{tabular}

ADL Activities of daily living, Cl Confidence interval, FJS-12 Forgotten Joint Score12, KOOS Knee Injury and Osteoarthritis Outcome Score, KSS New Knee Society Score, $P R O M$ patient-reported outcome measure, $Q O L$ Quality of life; ${ }^{a}$, Weak correlation; ${ }^{\mathrm{b}}$, Moderate correlation

Boldface means statistically significant 
Table 6 Results of univariable and multivariable regression analyses with numbness score as the response variable

\begin{tabular}{|c|c|c|c|c|c|c|}
\hline \multirow[t]{2}{*}{ Variables } & \multicolumn{3}{|l|}{ Univariable } & \multicolumn{3}{|c|}{ Multivariable } \\
\hline & $\begin{array}{l}\text { regression } \\
\text { coefficient }\end{array}$ & $95 \% \mathrm{Cl}$ & $P$-value & $\begin{array}{l}\text { regression } \\
\text { coefficient }\end{array}$ & $95 \% \mathrm{Cl}$ & $P$-value \\
\hline Age at surgery (years) & 0.0049 & $-0.01-0.02$ & 0.58 & 0.001 & $-0.02-0.02$ & 0.91 \\
\hline Follow-up (months) & 0.004 & $-0.001-0.003$ & 0.12 & & & \\
\hline BMl at time of surgery $\left(\mathrm{kg} / \mathrm{m}^{2}\right)$ & -0.04 & -0.07 to -0.04 & 0.03 & -0.03 & $-0.07-0.004$ & 0.08 \\
\hline Preoperative knee flexion angle $\left(^{\circ}\right)$ & 0.004 & $-0.05-0.01$ & 0.40 & & & \\
\hline Postoperative knee flexion angle $\left({ }^{\circ}\right)$ & 0.009 & $-0.003-0.02$ & 0.17 & & & \\
\hline Sex (male) & 0.2 & $-0.16-0.56$ & 0.27 & 0.21 & $-0.18-0.59$ & 0.29 \\
\hline Diagnosis & & & 0.06 & & & \\
\hline ON [vs. OA] & 0.61 & $0.07-1.16$ & 0.03 & & & \\
\hline RA [vs. OA] & -0.21 & $-0.78-0.37$ & 0.48 & & & \\
\hline Preoperative $\mathrm{K}-\mathrm{L}$ grade & & & 0.14 & & & \\
\hline $\begin{array}{l}\mathrm{K}-\mathrm{L} \text { grade } 2 \\
\text { [vs. Grade 1] }\end{array}$ & 0.95 & $-1.91-3.81$ & 0.51 & 1.38 & $-1.47-4.42$ & 0.27 \\
\hline $\begin{array}{l}\mathrm{K}-\mathrm{L} \text { grade } 3 \\
\text { [vs. Grade 1] }\end{array}$ & 1.61 & $-1.20-4.42$ & 0.26 & 2.12 & $-0.69-4.93$ & 0.14 \\
\hline $\begin{array}{l}\mathrm{K}-\mathrm{L} \text { grade } 4 \\
\text { [vs. Grade 1] }\end{array}$ & 1.64 & $-1.15-4.44$ & 0.25 & 2.32 & $-0.49-5.13$ & 0.11 \\
\hline Surgical method [UKA] & 0.3 & $-0.07-0.66$ & 0.11 & 0.29 & $-0.19-0.78$ & 0.23 \\
\hline Incision [Midline] & 0.34 & $0.05-0.62$ & 0.02 & 0.35 & $0.003-0.69$ & 0.04 \\
\hline Arthrotomy & & & 0.08 & & & \\
\hline Midvastus [vs. Medial parapatellar] & 0.19 & $-0.23-0.60$ & 0.38 & & & \\
\hline Subvastus [vs. Medial parapatellar] & -0.23 & $-0.58-0.12$ & 0.20 & & & \\
\hline Trivector [vs. Medial parapatellar] & 0.39 & $-0.41-1.20$ & 0.34 & & & \\
\hline
\end{tabular}

Cl Confidence interval, BMI Body mass index, K- L Kellgren-Lawrence, OA Osteoarthritis, ON Osteonecrosis, RA Rheumatoid arthritis, UKA Unicondylar knee arthroplasty

Boldface means statistically significant

Better (higher) numbness score, male sex, and better knee flexion angle positively affected kneeling ability.

Several studies, such as the Oxford Knee Score (OKS), KSS, WOMAC, and KOOS [11, 13, 14], have reported that numbness did not correlate with PROMs. However, the present study demonstrated that our numbness score showed weak correlation with KSS-Expectation, KSS-Activities, KSS-Total, KOOS-Activities of Daily Living (ADL), KOOS-Sports, and KOOS-Quality of Life (QOL), and moderate correlations with KSS-Symptoms, KSS-Satisfaction, KOOS-Symptoms, KOOS-Pain, and the FJS-12. The numbness score may detect symptoms related to not only hyperesthesia but also to other sensory abnormalities because our numbness score method was more subjective than the numbness assessment methods used in previous reports $[13,31]$. Therefore, the numbness score could detect numbness experienced by patients in a broad sense, including joint awareness, and was thus correlated with each PROM and its subscales.

In the current study, compared with midline incision, anteromedial incision was a risk factor for poor numbness score (univariable: regression coefficient $=0.34$,
95\% $\mathrm{CI}=0.05-0.62, p=0.02$, multivariable: regression coefficient $=0.35,95 \% \mathrm{CI}=0.003-0.69, p=0.04)$. Several studies on the relationship between incision and numbness have been reported [26, 32, 33]. Similar to the results of our study, the results of Hassaballa et al. [33] showed that anteromedial incision caused a wider area of alteration in skin sensation than midline incision in a cohort of 38 TKAs and 40 UKAs with a minimum of 18 months of follow-up. Additionally, Laffose et al. [26] compared 31 TKAs performed via an anterolateral incision with 32 TKAs performed via a midline incision and found that an anterolateral incision resulted in a smaller area of numbness around the knee and that a smaller area of numbness correlated with better outcomes on the WOMAC and KOOS. A medially located skin incision could cause a wider area of paresthesia on the front of the knee because sensory nerve branches run across the front of the knee from the medial side [34]. In general, many knee arthroplasties are performed through a medial arthrotomy, which provides excellent surgical exposure in combination with midline or anteromedial incision [26], but anterolateral incision requires a longer 
Table 7 Results of univariable and multivariable regression analyses with KSS - kneeling as the response variable

\begin{tabular}{|c|c|c|c|c|c|c|}
\hline \multirow[t]{2}{*}{ Variables } & \multicolumn{3}{|l|}{ Univariable } & \multicolumn{3}{|c|}{ Multivariable } \\
\hline & $\begin{array}{l}\text { Regression } \\
\text { coefficient }\end{array}$ & $95 \% \mathrm{Cl}$ & $P$-value & $\begin{array}{l}\text { Regression } \\
\text { coefficient }\end{array}$ & $95 \% \mathrm{Cl}$ & $P$-value \\
\hline Age at surgery (years) & -0.009 & $-0.03-0.01$ & 0.40 & -0.02 & $-0.04-0.02$ & 0.50 \\
\hline Follow-up (months) & -0.008 & -0.01 to -0.002 & 0.01 & -0.0008 & $-0.01-0.009$ & 0.87 \\
\hline BMl at time of surgery $\left(\mathrm{kg} / \mathrm{m}^{2}\right)$ & -0.007 & $-0.05-0.03$ & 0.71 & -0.006 & $-0.05-0.03$ & 0.75 \\
\hline Preoperative knee flexion angle $\left(^{\circ}\right)$ & 0.002 & $-0.009-0.01$ & 0.78 & & & \\
\hline Postoperative knee flexion angle $\left(^{\circ}\right)$ & 0.02 & $0.008-0.04$ & 0.002 & 0.01 & $0.0004-0.03$ & 0.04 \\
\hline Sex [male] & 0.92 & $0.51-1.33$ & $<0.0001$ & 0.94 & $0.53-1.34$ & $<0.0001$ \\
\hline Diagnosis & & & 0.27 & & & \\
\hline ON [vs. OA] & 0.21 & $-0.43-0.86$ & 0.51 & & & \\
\hline RA [vs. OA] & 0.52 & $-0.15-1.20$ & 0.13 & & & \\
\hline Preoperative $\mathrm{K}-\mathrm{L}$ grade & & & 0.80 & & & \\
\hline K-L grade 2 [vs. Grade 1] & -1.47 & $-4.86-1.91$ & 0.39 & & & \\
\hline K-L grade 3 [vs. Grade 1] & -1.19 & $-4.51-2.14$ & 0.48 & & & \\
\hline K-L grade 4 [vs. Grade 1] & -1.21 & $-4.51-2.10$ & 0.47 & & & \\
\hline Surgical method [UKA] & 0.42 & $-0.008-0.85$ & 0.05 & 0.38 & $-0.23-0.99$ & 0.22 \\
\hline Incision [Midline] & -0.20 & $-0.53-0.14$ & 0.25 & -0.44 & $-0.96-0.07$ & 0.09 \\
\hline Arthrotomy & & & 0.48 & & & \\
\hline Midvastus [vs. Medial parapatellar] & 0.26 & $-0.23-0.74$ & 0.30 & & & \\
\hline Subvastus [vs. Medial parapatellar] & 0.33 & $-0.08-0.74$ & 0.11 & & & \\
\hline Trivector [vs. Medial parapatellar] & 0.25 & $-0.70-1.20$ & 0.61 & & & \\
\hline Numbness score & 0.22 & $0.11-0.33$ & 0.0002 & 0.19 & $0.07-0.30$ & 0.001 \\
\hline
\end{tabular}

CI Confidence interval, BMI Body mass index, K- L Kellgren-Lawrence, OA Osteoarthritis, ON Osteonecrosis, RA Rheumatoid arthritis, UKA Unicondylar knee arthroplasty

Boldface means statistically significant

incision and operation time [32], which is why there was no patient with an anterolateral incision in our cohort. A midline incision does not necessarily prevent numbness but appears to decrease postoperative numbness around the knee relative to that for anteromedial incision.

Our study results showed that kneeling ability was better for male sex than for female sex (univariable: regression coefficient $=0.92,95 \% \mathrm{CI}=0.51-1.33, p<0.0001$; multivariable: regression coefficient $=0.94$, 95\% $\mathrm{CI}=0.53-1.34, p<0.0001)$. As in our study, Smith et al. [35] reported that kneeling was easier for men than for women. A meta-analysis of 29,993 TKA cases reported that women tended to complain more about persistent postoperative pain than men [36]. The results of that study support those of this study showing that women complained more of kneeling difficulties.

The current study revealed that better postoperative knee flexion was significantly associated with better kneeling (univariable: regression coefficient $=0.02$, $95 \% \mathrm{CI}=0.008-0.04, p=0.002$, multivariable: regression coefficient $=0.01,95 \% \mathrm{CI}=0.0004-0.003, p=0.04)$. In a biomechanical study of TKA on cadaveric knees, Wilkens et al. [37] reported that patellofemoral contact pressure increased with knee flexion angles of $90^{\circ}-120^{\circ}$ in kneeling, but the pressure decreased for angles $>120^{\circ}$ and decreased to the same degree as the non-flexion knee at $135^{\circ}$. Their study results appear to support the present study results showing that kneeling ability was better with greater knee flexion angle.

The univariable and multiple regression analyses indicated that lower numbness score (greater numbness) was a risk factor of kneeling difficulty (univariable: regression coefficient $=0.22,95 \% \mathrm{CI}=0.11-0.33, p=0.0002$, multivariable: regression coefficient $=0.19, \quad 95 \%$ $\mathrm{CI}=0.07-0.30, p=0.001$ ). Several authors have reported correlations between numbness and kneeling ability $[32,33]$. Tsukada et al. [32] reported that a larger area of numbness in the front of knees post-TKA negatively correlated with kneeling. Additionally, in a study by Hassaball et al. [33], patients post-TKA or UKA who could not kneel had significantly wider surface area of sensitivity and hypersensitivity in the front of their knees than those who could kneel. However, in a study that included 49 TKAs, Sharkey et al. [11] found that numbness did not correlate with the OKS, which includes items related to subjective symptoms, such as pain, and items related to 
complex movements, such as kneeling. In the present study with a larger cohort (394 knees) than in Sharkey's study, subjective numbness around the surgical wound correlated with both subjective symptoms and kneeling, a result that differed from their report.

No report has shown that UKA provides better ability to kneel than TKA. When compared with TKA, the current study suggested that UKA had a positive effect on kneeling in univariate analysis, although the result was not significant $(p=0.054)$ and did not significantly affect kneeling in the multivariate analysis $(p=0.22)$. Similar to our study, Hassaballa et al. reported that UKA was not significantly advantageous over TKA in kneeling ability. Artz et al. [38] reported that approximately $35 \%$ of postUKA and $45 \%$ of post-TKA patients could not kneel, but they did not state whether or not the difference was significant. Kneeling is affected by multiple factors and may be less affected by the difference between UKA and TKA.

Numbness is a minor complication, but it can correlate with symptoms, such as joint awareness and pain, and can affect functions, including kneeling. In our study, more than half (56.9\%) of the patients experienced some degree of numbness around the surgical wound after knee arthroplasty. Based on this finding, surgeons can share with patients the prediction of possible postoperative symptoms by providing information on the relationship between numbness and clinical outcomes before surgery during the informed consent process. In addition, this finding may help surgeons choose surgical techniques since we found that an anteromedial incision may be a risk factor for postoperative numbness.

In our cohort, 514 knee arthroplasties (mean age, 72.9 years) were performed for about 12 years, which was a comparable rate of 40 women aged 70-74years who underwent TKA per 10,000 per year in Denmark [39]. Based on the rates of knee arthroplasty and results of the power analysis described above, the sample size for this study was judged to be appropriate.

This study had several limitations. First, the numbness score did not objectively assess the location of the numbness. Previous studies have adopted objective assessments for numbness [13, 31]. In contrast, this study adopted a subjective assessment using a numbness score that asked about numbness "around the surgical wound". Therefore, the numbness score may not have reflected the exact nature and location of the numbness complained of by the patients. However, the reliability of the numbness score was confirmed by calculating the ICC (see the section on "statistical analysis"), so the numbness score was associated with the degree of patient-reported numbness in our study. Second, a retrospective study design was used, and the mean follow-up duration of 28.0 months was relatively short. It has been reported that complaints of numbness were more common in the first 3 years after TKA than from 6years onward after TKA [40], suggesting that numbness would decrease as the duration increases. Therefore, our mean follow-up may have occurred when numbness was frequent. Third, patients who underwent bilateral surgeries, which can be a confounder, were included, but the patients were asked to report PROMs for each knee independently. As a reference, correlation and regression analyses were performed on the data based on 311 knees in 311 patients, excluding patients who had undergone surgery on both knees. The results were comparable to those obtained from the 394 knees (Additional file 1). Fourth, the cohort underwent knee replacement surgery over a relatively long period of 12 years, from May 2007 to January 2019. Over these 12 years, there have been advances in perioperative management with the development of the enhanced recovery after surgery (ERAS) program and surgical techniques $[6,41]$. There was no significant change in the surgical technique of TKA in our cohort over 12 years, as TKA was consistently performed using conventional instruments to achieve mechanical alignment. Although ERAS has been reported to reduce early postoperative complications and shorten hospital stays [41], the effect of ERAS on PROMs at a mean of 28 months after surgery is unknown in this cohort. Fifth, although psychiatric disorders such as depression and anxiety have been reported to affect outcomes after knee arthroplasty [41, 42], the present study did not exclude patients with psychiatric disorders, which may have affected the PROMs. However, Buller et al. reported that 4.1 and $1.7 \%$ of $8,379,490$ patients who underwent TKA or total hip arthroplasty had depressive disorders and anxiety disorders, respectively, [42] and it is expected that the general cohort after knee arthroplasty would include patients with some form of psychiatric disorders. Therefore, patients with psychiatric disorders in our cohort were not excluded.

\section{Conclusions}

Patient-reported numbness around the surgical wound after knee replacement correlated with postoperative PROMs and affected kneeling. The numbness score mainly correlated with symptoms, patient satisfaction, and joint awareness. Compared with midline incision, anteromedial incision was found to be a risk factor of lower numbness score (greater numbness). Higher numbness score (less numbness), male sex, and better knee flexion angle were positively associated with better kneeling ability.

\section{Abbreviations}

ADL: Activity of daily living; BMl: Body mass index; Cl: Confidence interval; FJS-12: Forgotten Joint Score-12; ERAS: Enhanced recovery from surgery; HTO: 
High tibial osteotomy; ICC: Intraclass correlation; K-L: Kellgren-Lawrence; KOOS: Knee Injury and Osteoarthritis Outcome Score; KSS: New Knee Society Score; MCL: Medial collateral ligament; OA: Osteoarthritis; OKS: Oxford knee score; ON: Osteonecrosis; PROM: Patient-reported outcome measure; QOL: Quality of life; RA: Rheumatoid arthritis; SD: Standard deviation; TKA: Total knee arthroplasty; UKA: Unicondylar knee arthroplasty; WOMAC: Western Ontario and McMaster Universities Osteoarthritis Index.

\section{Supplementary Information}

The online version contains supplementary material available at https://doi. org/10.1186/s12891-021-04971-6.

\section{Additional file 1.}

\section{Acknowledgements}

We would like to thank Enago (www.enago.jp) for English editing.

\section{Authors' contributions}

MI designed the study and completed the manuscript draft. KO supervised the research design and writing of the manuscript. All authors made contributions to the conception and outline of the study. All authors read and approved the final manuscript.

\section{Funding}

This research received no specific grant from any funding agency in the public, commercial, or not-for-profit sectors.

\section{Availability of data and materials}

The datasets used and/or analyzed during the study are available from the corresponding author upon reasonable request.

\section{Declarations}

\section{Ethics approval and consent to participate}

This study was approved by the Medical Ethics Committee of Tokyo Women's Medical University (approval number: 4578). Informed consent in this study was provided by an opt-out option.

\section{Consent for publication}

Not applicable.

\section{Competing interests}

$\mathrm{KO}$ is a paid speaker of Smith and Nephew, Inc. and Zimmer Biomet, Inc. The other authors declare that they have no competing interests.

Received: 26 July 2021 Accepted: 20 December 2021

Published online: 03 January 2022

\section{References}

1. Diduch DR, Insall JN, Scott WN, Scuderi GR, Font-Rodriguez D. Total knee replacement in young, active patients. Long-term follow-up and functional outcome. J Bone Joint Surg Am. 1997;79:575-82.

2. Parratte S, Pagnano MW, Trousdale RT, Berry DJ. Effect of postoperative mechanical axis alignment on the fifteen-year survival of modern, cemented total knee replacements. J Bone Joint Surg. 2010;92A:2143-9.

3. Martin JR, Beahrs TR, Stuhlman CR, Trousdale RT. Complex primary total knee arthroplasty: long-term outcomes. Jbjs. 2016;98:1459-70.

4. Sharma S, Nicol F, Hullin MG, McCreath SW. Long-term results of the uncemented low contact stress total knee replacement in patients with rheumatoid arthritis. J Bone Joint Surg Br. 2005:87:1077-80.

5. Parratte S, Ollivier M, Lunebourg A, Abdel MP, Argenson JN. Long-term results of compartmental arthroplasties of the knee: long term results of partial knee arthroplasty. Bone Joint J. 2015;97-b:9-15.

6. Price AJ, Alvand A, Troelsen A, Katz JN, Hooper G, Gray A, et al. Knee replacement. Lancet (London, England). 2018;392:1672-82.
7. Maradit Kremers H, Larson DR, Crowson CS, Kremers WK, Washington RE, Steiner CA, et al. Prevalence of total hip and knee replacement in the United States. J Bone Joint Surg Am. 2015;97:1386-97.

8. Klug A, Gramlich Y, Rudert M, Drees P, Hoffmann R, Weissenberger M, et al The projected volume of primary and revision total knee arthroplasty will place an immense burden on future health care systems over the next 30 years. Knee Surg Sports Traumatol Arthrosc. 2021;29(10):3287-98.

9. Sloan M, Premkumar A, Sheth NP. Projected volume of primary total joint arthroplasty in the U.S., 2014 to 2030. J Bone Joint Surg Am. 2018;100(17):1455-60.

10. Wood TJ, Petruccelli DT, Tushinski DM, Winemaker MJ, de Beer J. Nuisance symptoms in total joint arthroplasty: prevalence and impact on patient aatisfaction. J Arthroplast. 2020;35:661-70.

11. Sharkey PF, Miller AJ. Noise, numbness, and kneeling difficulties after total knee arthroplasty: is the outcome affected? J Arthroplast. 2011:26:1427-31.

12. Helito CP, Sobrado MF, Giglio PN, Bonadio MB, Pécora JR, Demange MK, et al. The use of negative-pressure wound therapy after total knee arthroplasty is effective for reducing complications and the need for reintervention. BMC Musculoskelet Disord. 2020;21:490.

13. Jariwala AC, Parthasarathy A, Kiran M, Johnston LR, Rowley DI. Numbness around the total knee arthroplasty surgical scar: prevalence and effect on functional outcome. J Arthroplast. 2017;32:2256-61.

14. Blackburn J, Wylde V, Greenwood R, Blom AW, Levy A. The effect of numbness on outcome from total knee replacement. Ann R Coll Surg Engl. 2017;99:385-9.

15. Scuderi GR, Bourne RB, Noble PC, Benjamin JB, Lonner JH, Scott WN The new knee society knee scoring system. Clin Orthop Relat Res. 2012;470:3-19.

16. Bellamy N, Buchanan WW, Goldsmith CH, Campbell J, Stitt LW. Validation study of WOMAC: a health status instrument for measuring clinically important patient relevant outcomes to antirheumatic drug therapy in patients with osteoarthritis of the hip or knee. J Rheumatol. 1988;15:1833-40.

17. Roos EM, Roos HP, Lohmander LS, Ekdahl C, Beynnon BD. Knee Injury and Osteoarthritis Outcome Score (KOOS)--development of a self-administered outcome measure. J Orthop Sports Phys Ther. 1998;28:88-96.

18. Hassaballa MA, Porteous AJ, Newman JH, Rogers CA. Can knees kneel? Kneeling ability after total, unicompartmental and patellofemoral knee arthroplasty. Knee. 2003;10:155-60.

19. Wylde V, Dixon S, Miller LL, Whitehouse MR, Blom AW. 5 year outcomes and survivorship of the triathlon total knee replacement: a cohort study. Acta Orthop Belg. 2017;83:259-67.

20. Behrend H, Giesinger K, Giesinger JM, Kuster MS. The "forgotten joint" as the ultimate goal in joint arthroplasty: validation of a new patientreported outcome measure. J Arthroplast. 2012;27:430-6.e431.

21. Thomsen MG, Latifi R, Kallemose $T$, Husted $H$, Troelsen A. Does knee awareness differ between different knee arthroplasty prostheses? A matched, case-control, cross-sectional study. BMC Musculoskelet Disord. 2016;17:141.

22. Baumann F, Krutsch W, Worlicek M, Kerschbaum M, Zellner J, Schmitz $P$, et al. Reduced joint-awareness in bicruciate-retaining total knee arthroplasty compared to cruciate-sacrificing total knee arthroplasty. Arch Orthop Trauma Surg. 2018;138:273-9.

23. Baumann F, Ernstberger T, Loibl M, Zeman F, Nerlich M, Tibesku C. Validation of the German forgotten joint score (G-FJS) according to the COSMIN checklist: does a reduction in joint awareness indicate clinical improvement after arthroplasty of the knee? Arch Orthop Trauma Surg. 2016;136:257-64.

24. Thomsen MG, Latifi R, Kallemose T, Barfod KW, Husted H, Troelsen A. Good validity and reliability of the forgotten joint score in evaluating the outcome of total knee arthroplasty. Acta Orthop. 2016;87:280-5.

25. Taniguchi H, Itoh M, Yoshimoto N, Itou J, Kuwashima U, Okazaki K. Noise after total knee arthroplasty has limited effect on joint awareness and patient-reported clinical outcomes: retrospective study. BMC Musculoskelet Disord. 2020;21:115.

26. Laffosse JM, Potapov A, Malo M, Lavigne M, Vendittoli PA. Hypesthesia after anterolateral versus midline skin incision in TKA: a randomized study. Clin Orthop Relat Res. 2011;469:3154-63.

27. Insall JN, Binazzi R, Soudry M, Mestriner LA. Total knee arthroplasty. Clin Orthop Relat Res. 1985:192:13-22. 
28. Kellgren JH, Lawrence JS. Radiological assessment of osteo-arthrosis. Ann Rheum Dis. 1957;16:494-502.

29. Schober P, Boer C, Schwarte LA. Correlation coefficients: appropriate use and interpretation. Anesth Analg. 2018;126:1763-8.

30. Shrout PE, Fleiss JL. Intraclass correlations: uses in assessing rater reliability. Psychol Bull. 1979;86:420-8.

31. Maniar RN, Singhi T, Nanivadekar A, Maniar PR, Singh J. A prospective randomized study in 20 patients undergoing bilateral TKA comparing midline incision to anterolateral incision. J Orthop Traumatol. 2017;18:325-33.

32. Tsukada S, Kurosaka K, Nishino M, Hirasawa N. Cutaneous hypesthesia and kneeling ability after total knee arthroplasty: a randomized controlled trial comparing anterolateral and anteromedial skin incision. J Arthroplast. 2018;33:3174-80.

33. Hassaballa M, Artz N, Weale A, Porteous A. Alteration in skin sensation following knee arthroplasty and its impact on kneeling ability: a comparison of three common surgical incisions. Knee Surg Sports Traumatol Arthrosc. 2012;20:1983-7.

34. Tanavalee A, Limtrakul A, Veerasethsiri P. Amarase C, Ngarmukos S. Area of skin numbness after total knee arthroplasty: does minimally invasive approach make any difference from standard approach? J Arthroplast. 2016;31:2499-503.

35. Smith JRA, Mathews JA, Osborne L, Bakewell Z, Williams JL. Why do patients not kneel after total knee replacement? Is neuropathic pain a contributing factor? Knee. 2019;26:427-34.

36. Lewis GN, Rice DA, McNair PJ, Kluger M. Predictors of persistent pain after total knee arthroplasty: a systematic review and meta-analysis. Br J Anaesth. 2015:114:551-61.

37. Wilkens KJ, Duong LV, McGarry MH, Kim WC, Lee TQ. Biomechanical effects of kneeling after total knee arthroplasty. J Bone Joint Surg Am. 2007;89:2745-51.

38. Artz NJ, Hassaballa MA, Robinson JR, Newman JH, Porteous AJ, Murray JR. Patient reported kneeling ability in fixed and mobile bearing knee arthroplasty. J Arthroplast. 2015;30:2159-63.

39. Bager CL, Karsdal M, Bihlet A, Thudium C, Byrjalsen I, Bay-Jensen AC. Incidence of total hip and total knee replacements from the prospective epidemiologic risk factor study: considerations for event driven clinical trial design. BMC Musculoskelet Disord. 2019;20:303.

40. Black R, Green C, Sochart D. Postoperative numbness of the knee following total knee arthroplasty. Ann R Coll Surg Engl. 2013;95:565-8.

41. Li J, Zhu H, Liao R. Enhanced recovery after surgery (ERAS) pathway for primary hip and knee arthroplasty: study protocol for a randomized controlled trial. Trials. 2019:20:599.

42. Buller LT, Best MJ, Klika AK, Barsoum WK. The influence of psychiatric comorbidity on perioperative outcomes following primary total hip and knee arthroplasty; a 17-year analysis of the National Hospital Discharge Survey database. J Arthroplast. 2015;30:165-70.

\section{Publisher's Note}

Springer Nature remains neutral with regard to jurisdictional claims in published maps and institutional affiliations.

Ready to submit your research? Choose BMC and benefit from:

- fast, convenient online submission

- thorough peer review by experienced researchers in your field

- rapid publication on acceptance

- support for research data, including large and complex data types

- gold Open Access which fosters wider collaboration and increased citations

- maximum visibility for your research: over $100 \mathrm{M}$ website views per year

At BMC, research is always in progress.

Learn more biomedcentral.com/submissions 